\title{
Ultrathin Tropical Tropopause Clouds (UTTCs): II. Stabilization mechanisms
}

\author{
B. P. Luo ${ }^{1}$, Th. Peter ${ }^{1}$, H. Wernli ${ }^{1}$, S. Fueglistaler ${ }^{1}$, M. Wirth ${ }^{2}$, C. Kiemle ${ }^{2}$, H. Flentje ${ }^{2}$, V. A. Yushkov ${ }^{3}$, V. Khattatov ${ }^{3}$, \\ V. Rudakov ${ }^{3}$, A. Thomas ${ }^{4}$, S. Borrmann ${ }^{4}$, G. Toci ${ }^{5}$, P. Mazzinghi ${ }^{6}$, J. Beuermann ${ }^{7}$, C. Schiller ${ }^{7}$, F. Cairo ${ }^{8}$, \\ G. Di Don-Francesco ${ }^{9}$, A. Adriani ${ }^{8}$, C. M. Volk ${ }^{10}$, J. Strom ${ }^{11}$, K. Noone ${ }^{12}$, V. Mitev ${ }^{13}$, R. A. MacKenzie ${ }^{14}$, \\ K. S. Carslaw ${ }^{15}$, T. Trautmann ${ }^{16}$, V. Santacesaria ${ }^{17}$, and L. Stefanutti ${ }^{18}$ \\ ${ }^{1}$ Institute for Atmospheric and Climate Science, ETH Zurich, Switzerland \\ ${ }^{2}$ Institute for Atmospheric Physics, DLR Oberpfaffenhofen, Germany \\ ${ }^{3}$ Central Aerological Observatory, Moscow, Russia \\ ${ }^{4}$ Institute for Atmospheric Physics, University of Mainz, Germany \\ ${ }^{5}$ Quantum Electronics Institute, National Research Council (IEQ-CNR), Florence, Italy \\ ${ }^{6}$ National Institute of Applied Optics, Florence, Italy \\ ${ }^{7}$ Institute I: Stratosphere, Forschungszentrum Jülich GmbH, Jülich, Germany \\ ${ }^{8}$ Institute for Atmospheric Science and Climate,CNR, Roma, Italy \\ ${ }^{9}$ ENEA Casaccia, Roma, Italy \\ ${ }^{10}$ Institut fr Meteorologie und Geophysik, Universität Frankfurt, Germany \\ ${ }^{11}$ Institute of Applied Environmental Research, Stockholm University, Sweden \\ ${ }^{12}$ Department of Meteorology, Stockholm University, Sweden \\ ${ }^{13}$ Observatoire cantonal, Neuchâtel, Switzerland \\ ${ }^{14}$ Environmental Science Department, Lancaster University, UK \\ ${ }^{15}$ School of the Environment, University of Leeds, UK \\ ${ }^{16}$ Institute of Meteorology, University of Leipzig, Germany \\ ${ }^{17}$ IROE - CNR "Nello Carrara", Firenze, Italy \\ ${ }^{18}$ Geophysica-GEIE - "CNR", Firenze, Italy
}

Received: 6 December 2002 - Published in Atmos. Chem. Phys. Discuss.: 19 March 2003 Revised: 25 June 2003 - Accepted: 25 June 2003 - Published: 29 July 2003

\begin{abstract}
Mechanisms by which subvisible cirrus clouds (SVCs) might contribute to dehydration close to the tropical tropopause are not well understood. Recently Ultrathin Tropical Tropopause Clouds (UTTCs) with optical depths around $10^{-4}$ have been detected in the western Indian ocean. These clouds cover thousands of square kilometers as 200-300 m thick distinct and homogeneous layer just below the tropical tropopause. In their condensed phase UTTCs contain only $1-5 \%$ of the total water, and essentially no nitric acid. A new cloud stabilization mechanism is required to explain this small fraction of the condensed water content in the clouds and their small vertical thickness. This work suggests a mechanism, which forces the particles into a thin layer, based on upwelling of the air of some $\mathrm{mm} / \mathrm{s}$ to balance the ice particles, supersaturation with respect to ice above and subsaturation below the UTTC. In situ measurements suggest that
\end{abstract}

Correspondence to: B. P. Luo

(Beiping.Luo@ethz.ch) these requirements are fulfilled. The basic physical properties of this mechanism are explored by means of a single particle model. Comprehensive 1-D cloud simulations demonstrate this stabilization mechanism to be robust against rapid temperature fluctuations of $\pm 0.5 \mathrm{~K}$. However, rapid warming $(\Delta T>2 \mathrm{~K})$ leads to evaporation of the UTTC, while rapid cooling $(\Delta T<2 \mathrm{~K})$ leads to destabilization of the particles with the potential for significant dehydration below the cloud.

\section{Introduction}

Cirrus clouds may be remnants of outflow of deep convective systems (e.g. Danielsen, 1982; Sherwood and Dessler, 2000) or they may form as a result of in situ nucleation of ice crystals in the upper troposphere in the course of slow cooling and upwelling (e.g. Jensen et al., 2001). As described in the companion paper (Peter et al., 2003), recently 
Ultrathin Tropical Tropopause Clouds (UTTCs) have been investigated by means of simultaneous remote and in situ measurements. UTTCs are characterized by extensive layers of remarkable homogeneity with extremely low optical thickness, $\tau \approx 10^{-4}$, which is the consequence of (a) a low geometrical thickness of only $200-300 \mathrm{~m}$, and (b) low number densities, $n=5-10 \mathrm{~L}^{-1}$, of relatively small particles with radii $r \approx 5 \mu \mathrm{m}$. The low geometrical thickness and concomitant horizontal homogeneity comes as a surprise, as in situ formation of ice from preexisting droplets caused by homogeneous nucleation is expected to lead to cirrus clouds of at least $1.5 \mathrm{~km}$ thickness (Jensen et al., 2001). Also, outflow from deep convection cannot be expected to display this degree of homogeneity (unless, may be, subject to very high vertical wind shear). The low particle number densities and sizes are an even larger surprise, as they result in a condensed phase mass corresponding to a mixing ratio of just a few tens of ppbv (Peter et al., 2003; Luo et al., 2003; Thomas et al., 2002), i.e. much less than the total water available.

\section{Summary of UTTC measurements}

Here we briefly summarize information given in the companion paper (Peter et al., 2003) on the measurements performed during the APE-THESEO (Airborne Platform for Earth Observation - Third European Stratospheric Experiment on Ozone) campaign in February/March 1999 in the western Indian Ocean. UTTCs have the following characteristics:

1. the coverage of UTTCs was found to be high, around $31 \%$;

2. the vertical thickness of UTTCs is only $200-300 \mathrm{~m}$;

3. they reside only a few hundred meters below the cold point tropopause;

4. their horizontal extent may reach thousands of square kilometers;

5. the central parts of the cloud layer is characterized by a high degree of homogeneity;

6. they consist of water ice particles with little or no indication of co-condensed nitric acid;

7. the condensed matter in the cloud particles corresponds to only $25-100$ ppbv $\mathrm{H}_{2} \mathrm{O}$, or $1-5 \%$ of the total available water vapor;

8. ice crystal radii are 5-6 $\mu \mathrm{m}$, number densities 5$10 \mathrm{~L}^{-1}$.

As Luo et al. (2003) argue, the unique combination of high altitude and low number density makes UTTCs highly suited to serve as drying agent during the last step of dehydration of air directly before troposphere-to-stratosphere exchange. They investigate the conditions under which UTTCs serve this purpose, and conclude that UTTCs in a global average are likely to yield a lowering of $0.35 \mathrm{ppmv}$ of $\mathrm{H}_{2} \mathrm{O}$ in the air exchanged from the troposphere to the stratosphere.

\section{The UTTC paradox}

How is it possible that the condensed phase of UTTCs can consist of $25-100 \mathrm{ppbv}_{2} \mathrm{O}$, which is only $1-5 \%$ of the totally available water? And how can this at first sight very fragile arrangement be stable and form an only 200$300 \mathrm{~m}$ thick, relatively homogeneous layer, which extends over thousands of square kilometers? For comparison, in a controlled laboratory experiment with a container filled with 3 ppmv $\mathrm{H}_{2} \mathrm{O}$ at a total pressure of $90 \mathrm{hPa}$ it would require a tremendous effort to stabilize the temperature at $0.11 \mathrm{~K}$ below the frost point of $188.96 \mathrm{~K}$, in order to keep just $2 \%$ of the water in the condensed phase. Only one tenth of a degree warmer or colder and the particles would be gone or grow to twice the mass, either result conflicting with the observations. Furthermore, particles with 5-6 $\mu \mathrm{m}$ radius sediment by about $400 \mathrm{~m}$ per day, while they have been observed always a few hundred meters below the tropopause during five flights covering the period of one month. If they sedimented during their lifetime, the frost point would also have to descend, which is unlikely. The thinness, homogeneity, duration and persistent altitude of these layers demonstrate that nature is able to overcome this stabilization problem.

Three potential solutions come to mind:

(a) the natural clouds are not composed of ice;

(b) the particles are composed of ice, but they are nucleated in-situ and not in equilibrium with their environment, in contrast to the lab experiment envisaged above;

(c) they are composed of ice in equilibrium and subject to a delicate stabilization mechanism.

We will show that there are favorable conditions for (c), while (a) and (b) should be rejected.

Any kind of non-volatile material, such as mineral dust or meteoritic material can be excluded as source of UTTCs. There is no reason why, in the absence of very strong wind shear, such matter should accumulate in a distinct, very thin layer right below the tropopause. Also the in situ measurements suggest the condensed phase to consist mainly of water (Peter et al., 2003). Rather, it is conceivable that volatile compounds, such as those in $\mathrm{HNO}_{3}$-containing polar stratospheric cloud particles, might condense at the tropical tropopause (Hamill and Fiocco, 1988; Hervig and McHugh, 2002). About 5-10 ppbv of $\mathrm{HNO}_{3}$ condensed as a hydrate could explain the stability of the particles against temperature fluctuations. However, from the CVI-TDL (Counterflow Virtual-Impactor - Tunable Diode Laser, detection limit 
$\approx 0.2 \mathrm{ppb}$ ) measurements onboard Geophysica during the APE-THESEO campaign there is no evidence for $\mathrm{HNO}_{3}$ in the particles (see Luo et al., 2003). The measurements made on ER-2 flights in the tropics show a $\mathrm{HNO}_{3}$ mixing ratio typically $0.1-0.5 \mathrm{ppbv}$ (Jensen and Drdla, 2002), which is too low to explain either the HALOE extinctions (Jensen and Drdla, 2002) or the UTTCs. Furthermore, a detailed investigation of the UTTC lidar data reveals that evidence for a distinct difference between ice clouds and $\mathrm{HNO}_{3}$-hydrate clouds, as known from lidar measurements in the polar regions (Type-1 versus Type-2 polar stratospheric clouds), is missing.

Next, we investigate the possibility (b) that the layers consist of ice particles, which nucleate in slowly upwelling and cooling air masses and then sediment to lower subsaturated altitudes where they again evaporate. Though extreme wind shear could help forming thin layers initially, the survival of the particles requires $S_{\text {ice }}=1$ while they sediment by $400 \mathrm{~m} /$ day, which is unlikely. Assuming homogeneous nucleation of ice in background aerosol droplets, modeling work by Jensen et al. (2001) showed that this mechanism is suited for SVC formation and maintenance. However, SVCs maintained by continuous homogeneous nucleation with subsequent sedimentation and evaporation require an ice saturation ratio $S_{\text {ice }} \approx 1.6$ in the liquid phase (Koop et al., 2000), corresponding to a relative humidity of $160 \%$ with respect to ice in the gas phase (which can be assumed to be in equilibrium with the solution droplets). In contrast, the water vapor measurements during APE-THESEO shown in Fig. 1 reveal only slight supersaturations above the UTTC layer, reaching about $S_{\text {ice }} \approx 1.2$. Moreover, continuously nucleating SVCs must be geometrically much thicker than UTTCs. The minimum thickness of such clouds is at least $800 \mathrm{~m}$, as can be estimated from the necessity to reach $S_{\text {ice }} \approx 1.6$ (equivalent to a supercooling of $3-4 \mathrm{~K}$ below the frost point required for homogeneous ice nucleation in the background aerosol droplets). This condition is met $400 \mathrm{~m}$ above the frost point altitude (assuming constant $\mathrm{H}_{2} \mathrm{O}$ mixing ratio and a lapse rate of $10 \mathrm{~K} / \mathrm{km}$ ), so that the particles grow in free fall over $400 \mathrm{~m}$ and then need another $400 \mathrm{~m}$ under subsaturated conditions before they are completely evaporated. This is a lower bound, and Jensen et al. (2001) showed that clouds forming by this mechanism are indeed typically $1.5-2 \mathrm{~km}$ thick. In the case of homogeneous freezing, the particles would grow to sizes $>20 \mu \mathrm{m}$ when they fall from the level of nucleation to the level of ice saturation $(\sim 400 \mathrm{~m})$, which is also in clear contradiction to the observed size of $\sim 5 \mu \mathrm{m}$.

If there were ice nuclei (IN) enabling heterogeneous nucleation, this could considerably reduce the necessary supercooling, and hence allow for much thinner clouds. For example, silver iodide (AgI) is known as a very potent IN, and laboratory experiments suggest that $S_{\text {ice }} \approx 1.1(T=263.7 \mathrm{~K})$ might suffice to activate a fraction of $10^{-5}$ in an ensemble of pure water droplets including $45 \mathrm{~nm}$ AgI nuclei (median

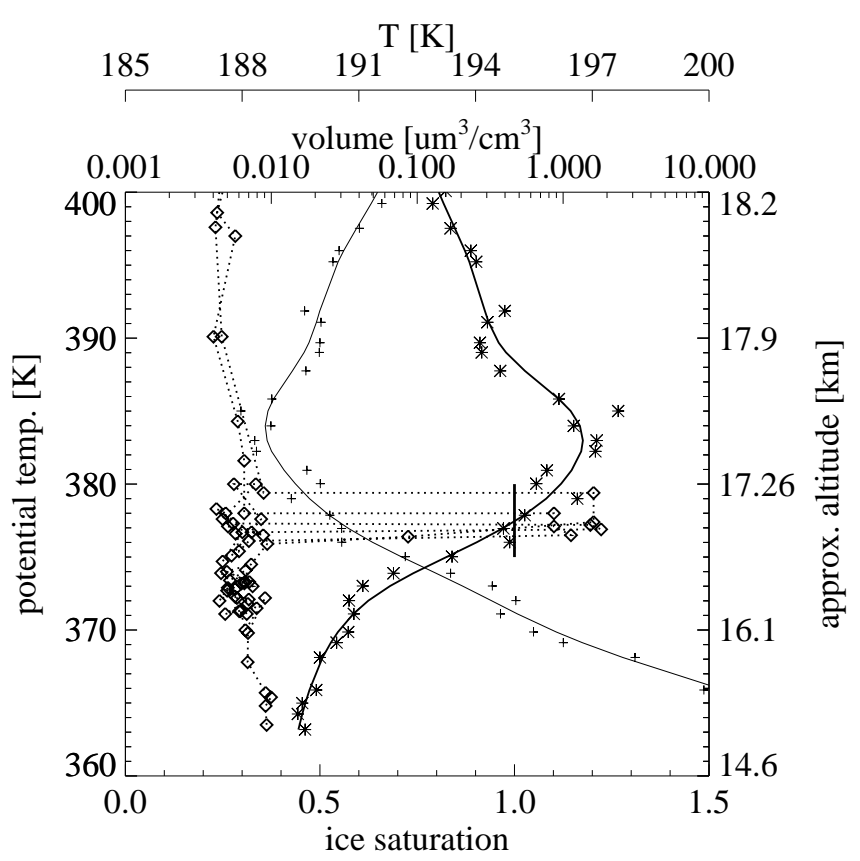

Fig. 1. Profiles of particulate volume density on 24 February 1999 measured by the FSSP-300 (diamonds), 100-m vertical averages of temperature (crosses) and of the ice saturation ratio $S_{\text {ice }}$ calculated from the measurement by the Ly- $\alpha$ hygrometer FLASH (stars), which is the second hygrometer on board Geophysica measuring gas-phase water only. The $S_{\text {ice }}=1$ level is marked by the vertical bar. The cold point tropopause is about $400 \mathrm{~m}$ above the centre of the UTTC. Temperatures are uncertain by $\pm 1 \mathrm{~K}$ and have been taken at the lower limit in order to achieve $S_{\text {ice }}=1$ level at cloud altitude.

radius) (Pruppacher and Klett, 1997). Provided that the heterogeneous freezing rate in solutions at constant saturation decreases with decreasing temperature (as is the case for the homogeneous rate, and also for the heterogeneous rate if the physical properties of the nucleation site, e.g. the contact angle, do not depend on temperature themselves), we can make a conservative estimate and apply the fraction of $10^{-5}$ found in the laboratory for the warm pure water droplets to solution droplets about $200 \mathrm{~m}$ above the UTTC (with $S_{\text {ice }} \approx 1.1$ ) in Fig. 1 . This would then imply that each of the approximately $10^{3} \mathrm{~cm}^{-3}$ background aerosol particles must contain an IN as potent as $\mathrm{AgI}$ in order to produce clouds as thin as the observed UTTCs, a quite unlikely scenario. Furthermore, recent low-temperature laboratory measurements suggest that insoluble particles (such as dust or soot) lower the threshold for ice nucleation to only about $S_{\text {ice }}=1.3$ (Möhler et al., poster presentation, EGS-AGU General Assembly, Nice 2003). 

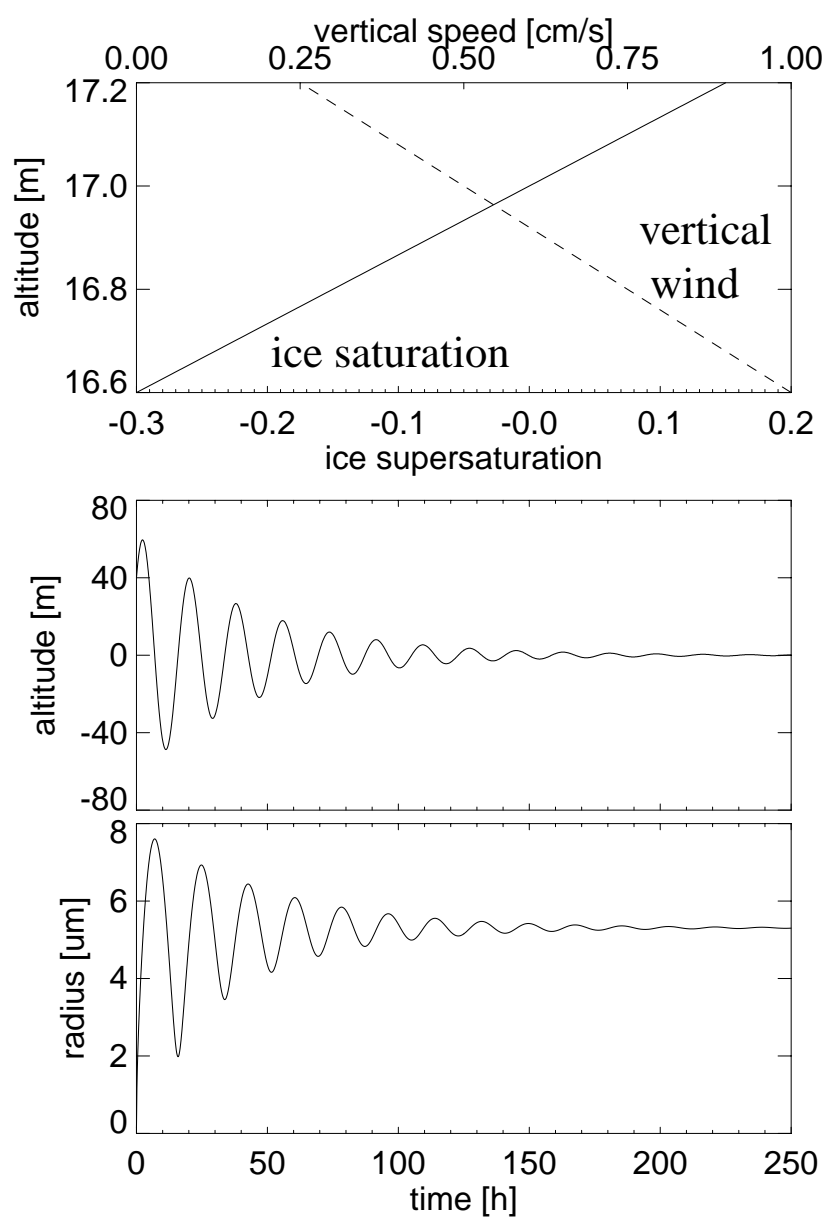

Fig. 2. One-particle simulation. Upper panel: prescribed ice saturation ratio and wind profile used for the calculation. Middle and lower panel: the altitude and size evolution of a small ice particle released $40 \mathrm{~m}$ above the equilibrium level.

\section{UTTC stabilization mechanism}

UTTCs require a completely new concept for cloud maintenance. Nucleation would become unnecessary to maintain the cloud if the ice particles were levitated by large-scale upwelling air motion, provided it is strong enough to balance their sedimentation speed, and provided there is some moderate supersaturation above the cloud. In such a case particles can stably oscillate about the altitude given by $S_{\text {ice }}=1$, i.e. $\sim 17.3 \mathrm{~km}$ (Fig. 1). This means, $S_{\text {ice }}=1$ defines a point of stability: if particles happen to sink below this level they enter a region of subsaturation, start to evaporate, deposit water in the gas phase, become lighter, and the upwelling drives them back to the $S_{\text {ice }}=1$ level; conversely, the air above is supersaturated, growth of the particles increases their weight, they deplete the gas phase, and then sediment back to the $S_{\text {ice }}=1$ level.

Here we model this mechanism in two steps: first we model the motion of a particle under the outlined conditions using a single-particle model with a fixed gas phase; second we use a comprehensive column model to describe the particle-gas interaction, and we compare the results of cloud thickness and density with the measurements (Sect. 5).

The coupled growth/evaporation and the vertical motion of ice particles in a presence of an upwelling velocity vair can be described by the following equations:

$$
\begin{aligned}
& \frac{d z}{d t}=v^{a i r}(z)-\frac{2 g \rho r^{2}}{9 \eta}, \\
& \frac{d r^{2}}{d t}=2 \frac{m}{\rho} D_{\mathrm{H}_{2} \mathrm{O}} n_{\mathrm{H}_{2} \mathrm{O}}^{\mathrm{vap}}\left[S_{\text {ice }}(z)-1\right] .
\end{aligned}
$$

Equation (1) describes the sedimentation of the ice particles. $z$ is the altitude, $r$ the radius of ice particles, $g$ the gravity constant $\left(980 \mathrm{~cm} / \mathrm{s}^{2}\right), \rho$ the density of ice $\left(0.91 \mathrm{~g} / \mathrm{cm}^{3}\right)$, $\eta$ the viscosity of air, respectively. Equation (2) describes the growth/evaporation of ice particles. $d r^{2} / d t$ is the timederivative of the second power of radius of ice particles. $S_{\text {ice }}$ is the saturation ratio with respect to ice, $m$ the mass of a water molecule, $D_{\mathrm{H}_{2} \mathrm{O}}$ the gas phase diffusion coefficient of water molecules, $n_{\mathrm{H}_{2} \mathrm{O}}$ is the molecular $\mathrm{H}_{2} \mathrm{O}$ density of the equilibrium vapor phase over ice. We used a highly simplified profile for $S_{\text {ice }}$ and $v_{\text {air }}$ in the single particle model as shown in the upper panel of Fig. 2. $n_{\mathrm{H}_{2} \mathrm{O}}^{\text {vap }}$ can be calculated from the vapor pressure over ice by using the ideal gas equation. We also fixed the temperature $T$ at $190 \mathrm{~K}$ and the total pressure at 90 mbar, which are used to calculate $n_{\mathrm{H}_{2} \mathrm{O}}^{\mathrm{V}}, D_{\mathrm{H}_{2} \mathrm{O}}$ and $\eta$ (Pruppacher and Klett, 1997). An example for the calculated trajectory of a single particle is shown in Fig. 2. The vertical speed has a slope of $-1.25 \mathrm{~cm} / \mathrm{s} / \mathrm{km}$ and equals to $0.5 \mathrm{~cm} / \mathrm{s}$ at $17 \mathrm{~km}$. A subtle point is that the vertical component of the wind must weaken with altitude in order to damp the oscillation of the ice particles about the $S_{\text {ice }}=1$ level (in the case of constant wind they oscillate without damping until they have flattened the relative humidity profile by continuous downward transport of water, while the solution of the coupled microphysical growth and sedimentation equations leads to an unstable oscillation if winds are increasing with altitude). In Fig. 3, the stability region of ice particles is shown. Depending on the initial size of the ice particles, they may stabilize even when they are $60 \mathrm{~m}$ below or above the equilibrium altitude.

The mechanism discussed here would not lead to efficient stabilization of the particle if it depended strongly on the profiles of $S_{\text {ice }}$ and $v_{\text {air }}$ in Fig. 2 (upper panel). However, this dependence is very moderate and the stabilization consequently very strong. Smaller gradients in $S_{\text {ice }}$, as they were frequently observed during APE-THESEO, lead to a larger altitude ranges of the stable region. Conversely, larger gradients, which have been observed only rarely, lead to somewhat smaller stability regions. The only requirement for the vertical wind, $v_{\text {air }}$, is that its gradient should be negative, with larger gradients leading to stronger damping of the oscillation. Changes in the overall wind speed simply lead to 
corresponding changes in the particle equilibrium size. In summary, the stabilization mechanism is relatively insensitive to the assumed input vertical profiles.

\section{UTTC column modeling}

In the column model, a vertical resolution of $10 \mathrm{~m}$ is used for the gas phase. Each individual particle is followed by its size and altitude. The simulation starts with a $1-\mathrm{km}$ thick SVC, which for example might have nucleated similarly to the cloud modeled by Jensen et al. (2001), for example nucleating in gravity waves. Alternatively, the particles may be due to flow out from deep convection. The base area can vary depending on the ice particle number density of the initial SVC. A total 5000 individual particles with monodisperse size distribution interacting with the gas phase are used in the present calculation (poly-disperse distributions do not change the results). The water molecules, condensing on or evaporating from the ice particles, are subtracted from or added to the corresponding gas phase altitude bin according to the following equation:

$\frac{d p}{d t}=\sum_{i} \frac{k T}{V_{b o x}} \frac{d N_{i}}{d t}$,

here $p$ is the water partial pressure and $V_{\mathrm{box}}$ is the gas phase volume of the vertical gas phase size bin (i.e. base area $x$ vertical resolution) and $N_{i}$ number of water molecules in ice particle $i . k$ is the Boltzmann constant. All the ice particles $i$ within the altitude bin are summed up. $d N_{i} / d t$ can be calculated from Eq. (2) and the radius of ice particles:

$\frac{d N_{i}}{d t}=\frac{2 \pi \rho r}{m} \frac{d r^{2}}{d t}$.

The prescribed vertical winds and the missing coupling to a radiation model should not compromise the principal microphysical results. We assume a vertical wind field that vanishes at $18.25 \mathrm{~km}$ altitude and increases downward with $0.4 \mathrm{~cm} / \mathrm{s}$ per kilometer. The results are shown in Fig. 4 . A slight warming (panel A) makes the SVC evaporate, but leaves a UTTC at $17.3 \mathrm{~km}$ behind, because $S_{\text {ice }}$ remains slightly larger than unity above this altitude (E). Between $12 \mathrm{~h}$ and $25 \mathrm{~h}$ particle radii (B) and number densities (D) are similar to those measured inside the UTTCs. The optical thickness of the simulated and measured clouds are very similar. However, there is a higher backscatter ratio and a thinner vertical thickness of the modeled cloud, as an idealized particle distribution, wind and temperature fields were used in the model. In particular, the larger vertical thickness of the measured UTTCs may be due to small-scale turbulence, which is not considered in the column model. Temperature fluctuations of $\pm 0.5 \mathrm{~K}$ were applied in the calculation to test the stability of the UTTCs. The aerosol backscatter ratio at $1064 \mathrm{~nm}$ in panel $\mathrm{C}$ shows that in addition a moist layer is left at the lower edge of the original SVC from particles sedimenting

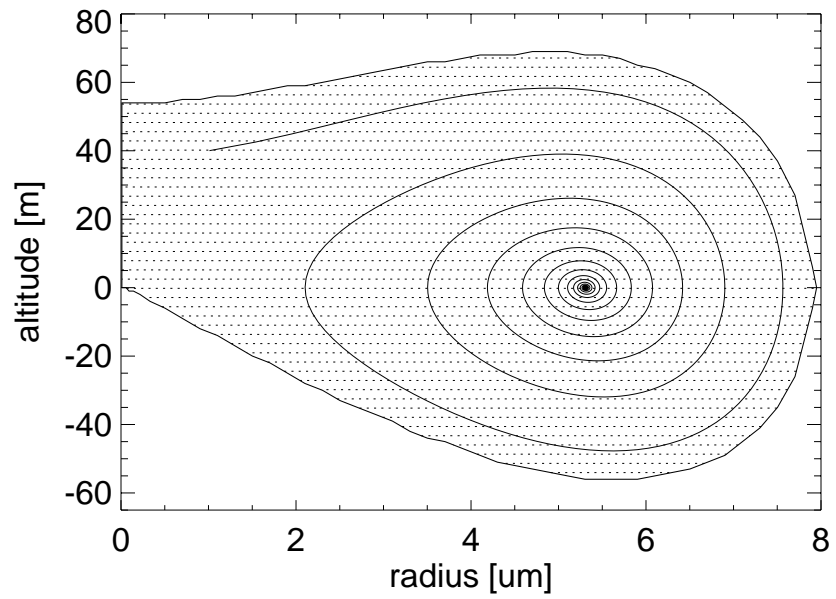

Fig. 3. Stability region of UTTCs. The ice particles starting within the stability region (given by initial size and altitude) survive and spiral to the equilibrium size and altitude. Particles outside this region evaporate at the lower altitude with $S_{\text {ice }}<1$. Trajectory refers to an ice particle with $r=1 \mu \mathrm{m}$ released $40 \mathrm{~m}$ above the equilibrium position. The altitude given here is relative to the equilibrium position of the UTTCs.

to this altitude before complete evaporation, leading to water uptake by the background droplets. Upon a cooling of $2 \mathrm{~K}$ from $25 \mathrm{~h}$ to $36 \mathrm{~h}$, the air below the UTTCs becomes supersaturated with respect the ice. The ice particles sediment into supersaturated air, where they grow to larger sizes and sediment rapidly enough to dehydrate the air significantly before it enters the stratosphere (see Luo et al., 2003). Had there been a warming instead of a cooling the UTTC would evaporate without effect on the gas phase water.

\section{Discussion}

The simulation requires upwelling velocities of $5 \mathrm{~mm} / \mathrm{s}$ just below the tropical tropopause in order to stabilize the UTTC. This value appears to be rather large considering the absence of moist convection and visible cloud formation. According to recent radiation calculations, mean net diabatic heating rates become positive above about $15 \mathrm{~km}$ and appear to reach values up to $0.5 \mathrm{~K} /$ day close to the tropical tropopause (Hartmann et al., 2001). Given the potential temperature profiles measured by the Geophysica in the vicinity of UTTCs, such diabatic heating rates would result in vertical velocities exhibiting a peak of about $2.5 \mathrm{~mm} / \mathrm{s}$ a few hundred meters below the tropopause, with a sharp decline above, similar to the study of Jensen et al. (2001). Clearly, large temporal and regional variations to these mean upwelling rates are possible. For example, the Indonesian region appears to permanently exhibit sinking motion of a few $\mathrm{mm} / \mathrm{s}$ in the tropopause layer (Sherwood, 2000), which has to be balanced by additional uplift over less convective regions in the 

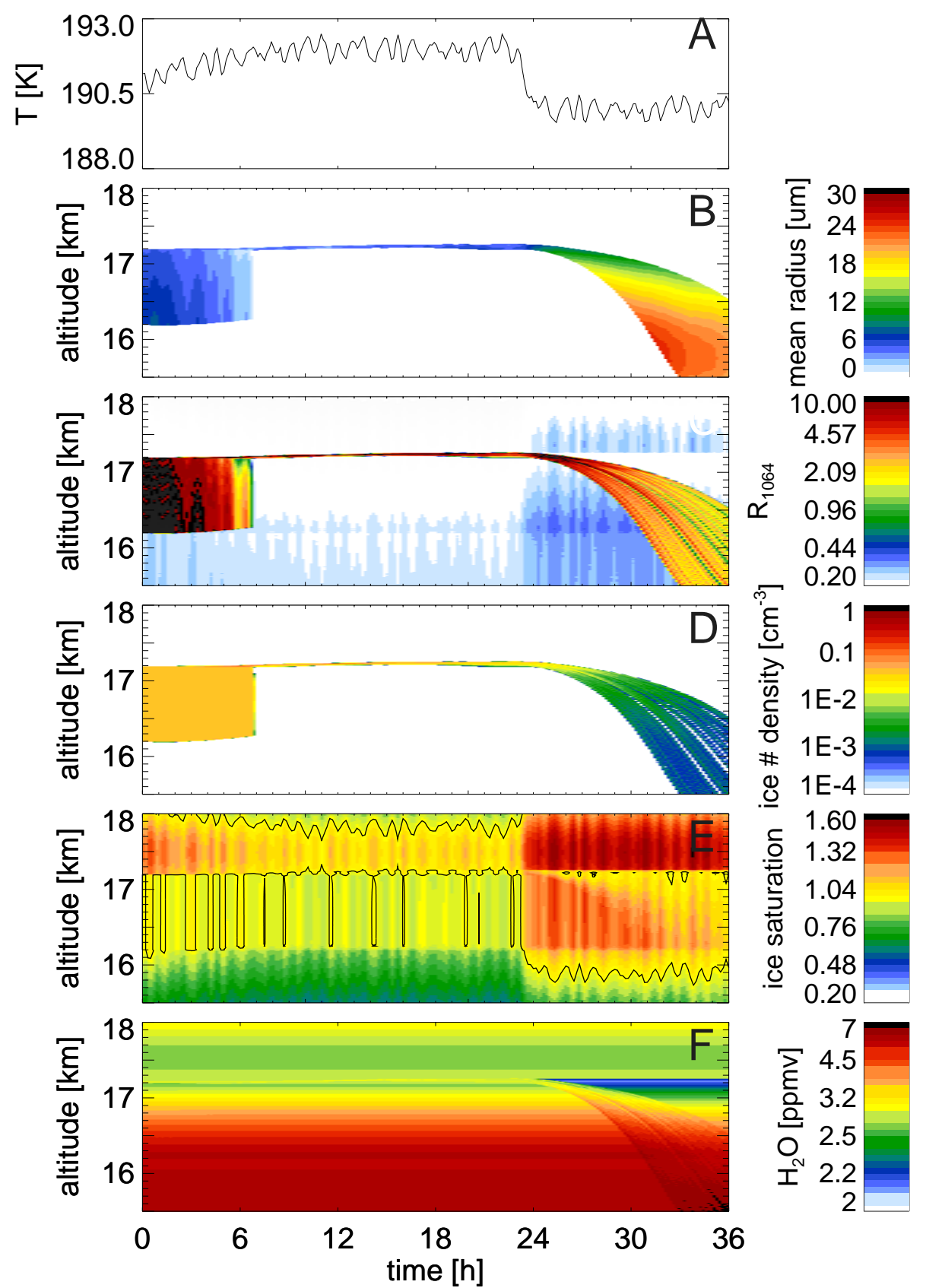

Fig. 4. Modelling of the 24-h evolution of a cirrus balanced by upwelling: 0-8 h slow evaporation of 1-km thick SVC due to warming of air column by $1 \mathrm{~K} ; 8-23 \mathrm{~h}$ persistent UTTC at $17.3 \mathrm{~km}$ stable against $0.5-\mathrm{K}$ fluctuations and accompanied by diffuse humidified $\mathrm{H}_{2} \mathrm{SO}_{4} / \mathrm{H}_{2} \mathrm{O}$ layer; $24-36 \mathrm{~h}$ cooling of air column by $2 \mathrm{~K}$ and subsequent destabilization of cloud with strong particle growth and sedimentation leading to dehydration. (A) temperature at $17.3 \mathrm{~km}$ altitude (assuming a vertical temperature profile as in Fig. 1); (B) mean radius of ice particles; (C) backscatter ratio at $1064 \mathrm{~nm}$ from ice crystals assuming spheroidal prolate shape with aspect ratio 0.5; (D) ice particle number density; (E) saturation ratio $\left(S_{\text {ice }}\right)$ with respect to ice, black contours mark the $S_{\text {ice }}=1$ level (i.e. equilibrium between gas and condensed phase); (F) gas phase water mixing ratio.

tropics. Indeed, VHF radar measurements over Christmas Island by Gage et al. (1991) reach monthly mean values of $3 \mathrm{~mm} / \mathrm{s}$ close to the tropopause, and in some months even up to $10 \mathrm{~mm} / \mathrm{s}$. Interestingly, peak upwelling velocities of $5 \mathrm{~mm} / \mathrm{s}$ just below the tropical tropopause are also consistent with the ozone measurements onboard the Geophysica when one assumes a simple balance between upwelling and photochemical production of ozone above $15.5 \mathrm{~km}$ as for example done by Folkins et al. (1999). Upwelling velocities increasing from 0 (at $14.9 \mathrm{~km}$ ) to a peak of $5 \mathrm{~mm} / \mathrm{s}$ at $16.7 \mathrm{~km}$ and dropping to typical stratospheric values $(0.2 \mathrm{~mm} / \mathrm{s})$ at higher altitudes yield an ozone profile in full agreement with the 
mean ozone profile during the APE-THESEO campaign.

Inspection of the assimilated data from the European Centre for Medium-range Weather Forecasts (ECMWF) on 24 and 27 February 1999 supports the existence of relatively large upward motions just below the cold point tropopause. This is seen in Figs. 5 and 6 . Figure 5 shows the lidar observations on 27 February 1999 for a flight leg in westeast direction at $10^{\circ} \mathrm{S}$ superimposed on the ECMWF vertical velocity field. The ECMWF data is in agreement with the hypothesis that the UTTC was generated by the $1-2 \mathrm{~km}$ thick Ci cloud which was slowly evaporating at the boundary of a broad region characterized by upward motion (colored red in Fig. 5), and that the UTTC was right above the center of the upwelling and almost at the top of a moist layer (dashed black curve). The upwelling of $5-10 \mathrm{~mm} / \mathrm{s}$ given by the ECMWF matches surprisingly well the requirement for the balance of the UTTC. UTTCs were also observed in regions with an upwelling motion of $\sim 5 \mathrm{~mm} / \mathrm{s}$ on 24 February 1999, see Fig. 6. On that day there were thicker cirrus some $2-3 \mathrm{~km}$ below the UTTC level, whereas they have presumably already evaporated higher up. On both days ECMWF vertical winds show a vertical gradient as required to stabilize the UTTCs. A comparison of Meteosat cloud images on that day with ECMWF precipitation and mid-tropospheric cloud cover reveals a very good agreement, showing no precipitation and scattered cloud cover along the flight path surrounded by three groups of precipitating Cbs at least $150 \mathrm{~km}$ from the flight path with cloud tops at $12-13 \mathrm{~km}$. Following a model of the tropical tropopause layer by Sherwood and Dessler (2000) one possible explanation for the stabilization of the UTTCs might be that it is part of the larger-scale upward motion required to match the strong descent above the Cbs. At that time of the year, according to ECMWF fields, such mesoscale regions of upwelling appear with some regularity in the western Indian ocean and last typically 24 hours. It must be emphasized that the temporal $(6 \mathrm{hr})$ and vertical $(\approx 1 \mathrm{~km})$ resolution of the ECMWF data is not sufficient to study the motions of tropical air in great detail and that it is not clear how strongly the vertical motion field is influenced by shortcomings of the model parameterizations. However, we checked all mission flights and find again remarkable support for the applicability of the analysis data: UTTCs were found only when ECMWF indicates both upwelling and sufficiently humid air, whereas they were absent otherwise. Slow uplift and sufficiently humid air are essential conditions for UTTCs anyway, may they be remnants from thicker clouds or formed in situ by suitable IN.

The temperature range, where UTTCs may remain upon the evaporation a thicker SVC during a warming event, is defined by the maximum ice saturation above the clouds (the upper limit, say 1.5) and the frost point of the SVC (including ice water content, say 1.1). This $\Delta S_{\text {ice }}=0.4$ corresponds to a temperature range of about $2 \mathrm{~K}$. We would argue that this temperature range is relatively large compared to the ubiquitous gravity waves in the tropics. Even the temperature

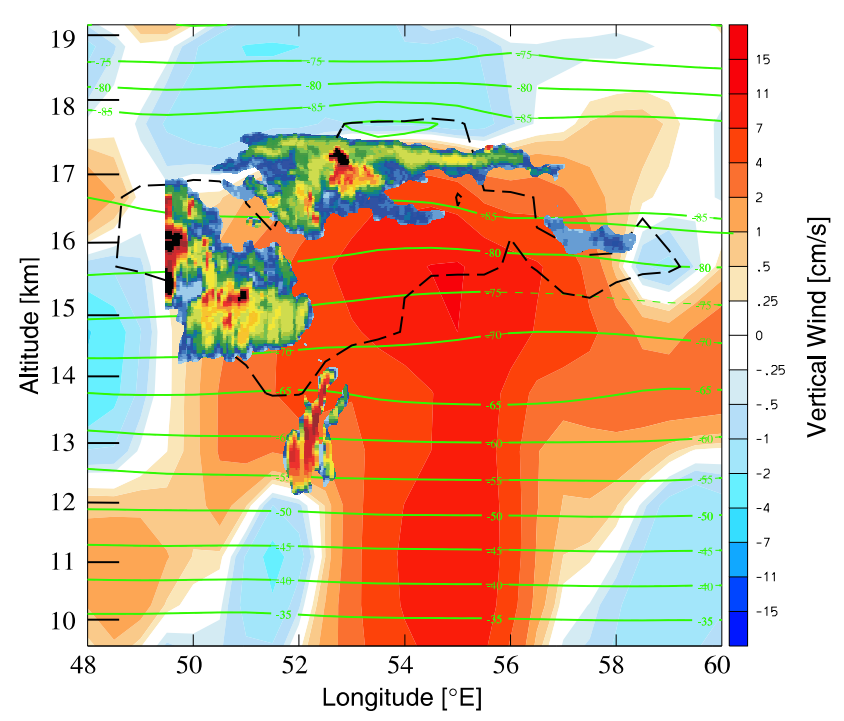

Fig. 5. ECMWF vertical winds $\left(\right.$ in $\mathrm{cm} \mathrm{s}^{-1}$, red $=$ upwelling, blue = downwelling), temperatures (in ${ }^{\circ} \mathrm{C}$, green contour lines, minimum at $-91^{\circ} \mathrm{C} 300 \mathrm{~m}$ above the UTTC) and relative humidity with respect to ice (black dashed line for $S_{\text {ice }}=110 \%$ ) along $10^{\circ} \mathrm{S}$ on 27 February 1999 at 6 UTC. Aerosol backscatter ratio $R_{1064}$ at 1064 nm measured by OLEX.

amplitudes of Kelvin waves might be small enough (Boehm and Verlinde, 2000), and such waves offer sufficient horizontal scale to simultaneously affect many 1000 s of square kilometres. However, waves on even larger scales might develop amplitudes too high for UTTCs to survive (i.e. they fully evaporate) or might lead to new ice nucleation. We feel that this offers a comfortable range for the generation of UTTCs, though a statistical analysis is beyond this paper.

Furthermore, Holton and Gettelman (2001) make the point of the above referenced paper is that horizontal velocities are typically orders of magnitude greater than vertical velocities near the tropical tropopause so that horizontal advection through "cold pools" near the tropopause must be considered. This seems consistent with the UTTCs discussed here, since the enhanced vertical motions that are required to explain the stabilization of the UTTCs are most likely associated with inertia-gravity waves of short vertical and long horizontal scale (and hence large horizontal and weak vertical velocities).

UTTCs are an important finding of the APE-THESEO campaign in the western Indian ocean. The ice particles appear to be wind-balanced. Hence, the size of these cloud particles is a direct measure of the upwelling velocity. The cloud model developed here is capable of describing the essential microphysical features of this new cloud type and reveals its dehydration potential. In a global perspective the quantification of the dehydration potential of UTTCs remains an open issue, which challenges our understanding of tropical upper tropospheric meteorology. 


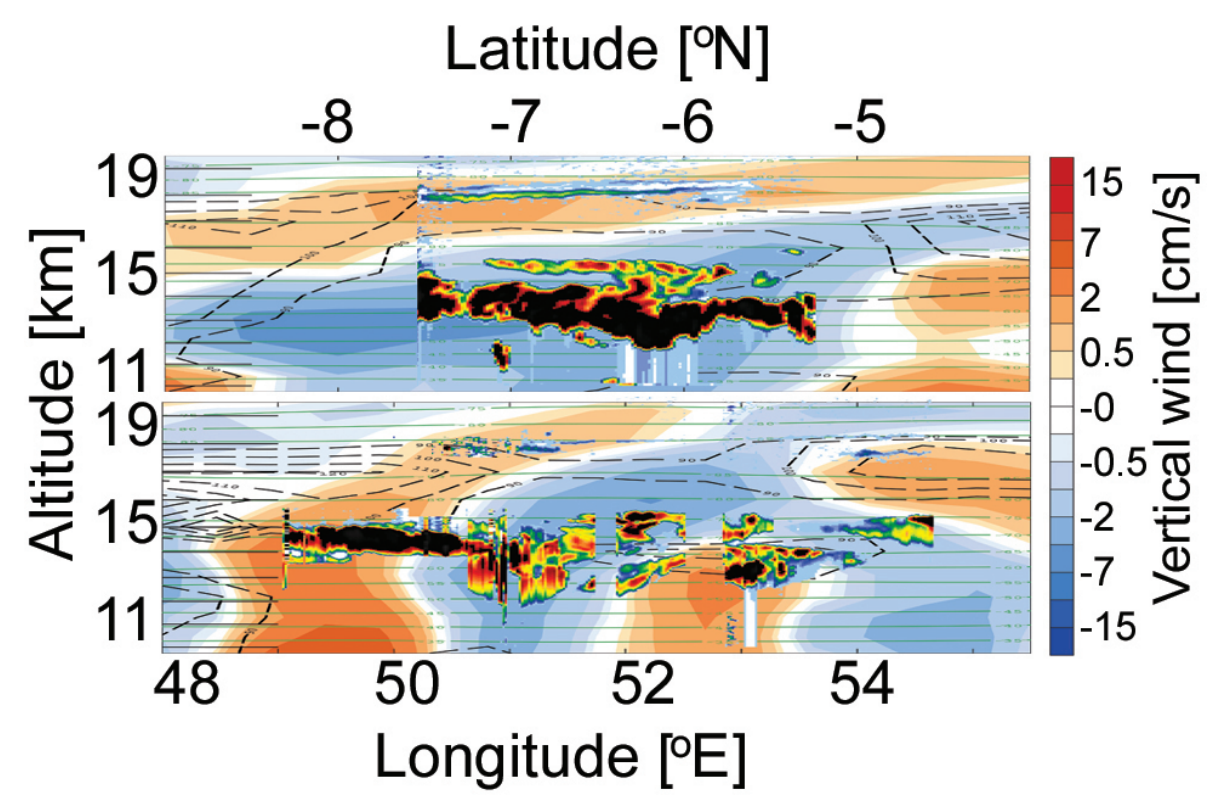

Fig. 6. Similar to Fig. 5, but for 24 February 1999. The top panel shows the North-South flight leg and the lower panel the East-West rebound flight leg on that day. The noise of the lidar signal at $\sim 50.5^{\circ} \mathrm{E}$ was due to icing of the windows of the lidar instrument. UTTCs are clearly visible around $18 \mathrm{~km}$ altitude, but only in regions with upwelling (reddish colours) and sufficient moisture (dashed lines corresponding to $S_{\text {ice }}=90 \%, 100 \%$ and $110 \%$ ).

Acknowledgements. We are grateful to Adrian Tompkins at ECMWF and Marcia Baker at the University of Washington for fruitful discussions. We thank the European Commission for funding the APE-THESEO campaign, and several national agencies for additional support.

\section{References}

Boehm, M. T. and Verlinde, J.: Stratospheric influence on uppertropospheric cirrus, Geophys. Res. Lett., 27, 3209-3212, 2000.

Danielsen, E. F.: A dehydration mechanism for the stratosphere, Geophys. Res. Lett. 9, 605-608, 1982.

Folkins, I., Loewenstein, M., Podolske, J., Oltmans, S. J., and Proffitt, M.: A barrier to vertical mixing at $14 \mathrm{~km}$ in the tropics: Evidence from ozonesondes and aircraft measurements, J. Geophys. Res., 104, 22 095-22 102, 1999.

Gage, K. S., McAfee, J. R., Carter, D. A., Ecklund, W. L., Riddle, A. C., Reid, G. C., and Balsley, B. B.: Long-term mean vertical motion over the tropical Pacific - wind profiling Doppler radar measurements, Science, 254, 1771-1773, 1991.

Hamill, P. and Fiocco, G.: Nitric acid aerosols at the tropical tropopause, Geophys. Res. Lett., 15, 1189-1192, 1988.

Hartmann, D. L., Holton, J. R., and Fu, Q.: The heat balance of the tropical tropopause, cirrus, and stratospheric dehydration, Geophys. Res. Lett., 28, 1969-1972, 2001.

Hervig, M. and McHugh, M.: Tropical Nitric Acid Clouds, Geophys. Res. Lett., 29, 10.1029/2001GL014271, 2002.

Holton, J. R. and Gettelman, A.: Horizontal transport and the dehydration of the stratosphere, Geophys. Res. Lett., 28, 2799-2802, 2001.
Jensen, E. J., Pfister, L., Ackerman, A. S., Toon, O. B., and Tabazadeh, A.: A conceptual model of the dehydration of air due to freeze-drying by optically thin, laminar cirrus rising slowly across the tropical tropopause, J. Geophys. Res., 106, 17237 $17252,2001$.

Jensen, E. J. and Drdla, K.: Nitric acid concentrations near the tropical tropopause: Implications for the properties of tropical nitric acid trihydrate clouds, Geophys. Res. Lett., 29(20), 2001, doi:101029/2002GL015190, 2002.

Koop, Th., Luo, B. P., Tsias, A., and Peter, Th.: Water activity as the determinant for homogeneous ice nucleation in aqueous solutions, Nature, 406, 611-614, 2000.

Luo, B. P., Peter, Th., Fueglistaler, S., et al.: Dehydration potential of ultrathin clouds at the tropical tropopause, Geophy. Res. Lett., 30, doi:10.1029/2002GL016737, 2003.

Peter, Th., Luo, B. P., Wernli, H., et al.: Ultrathin Tropical Tropopause Clouds (UTTCs): I. Cloud Morphology and Occurrence, Atmos. Chem. Phys., 3, 1083-1091, 2003.

Pruppacher, H. R. and Klett, J. D.: Microphysics of clouds and precipitation, Kluwer Akad. Publ., Dordrecht, 1997.

Sherwood, S. C.: A stratospheric 11 drain" over the maritime continent, Geophys. Res. Lett., 27, 677-680, 2000

Sherwood, S. C. and Dessler, A. E.: On the control of stratospheric humidity, Geophy. Res. Lett., 27, 2513-2516, 2000.

Thomas A., Borrmann, S., Kiemle, Ch., Cairo, F., Volk, M., Beuermann, J., Lepuchov, B., Santacesaria, V., Matthey, R., Rudakov, V., Yushkov, V., MacKenzie, A. R., and Stefanutti, L.: In situ measurements of background aerosol and subvisible cirrus in the tropical tropopause region, J. Geophys. Res., 107, doi:10.1029/2001jd001385, 2002. 